\title{
A Case Report of Ovarian Fibrothecoma in a Premenopausal Women with Recurrent Menorrhagia
}

\author{
Meral Rexhepi ${ }^{1,2 \star}$, Elizabeta Trajkovska ${ }^{3}$, Hysni Ismaili ${ }^{2}$, Majlinda Azemi ${ }^{4}$ \\ ${ }^{1}$ Department of Gynecology and Obstetrics, Clinical Hospital, Tetovo, Republic of Macedonia; ${ }^{2}$ Faculty of Medical Sciences, \\ University of Tetovo, Republic of Macedonia; ${ }^{3}$ Department of Pathology, Clinical Hospital, Tetovo, Republic of Macedonia; \\ ${ }^{4}$ University Clinic of Gynaecology and Obstetrics, University "Ss Cyril and Methodius", Skopje, Republic of Macedonia
}

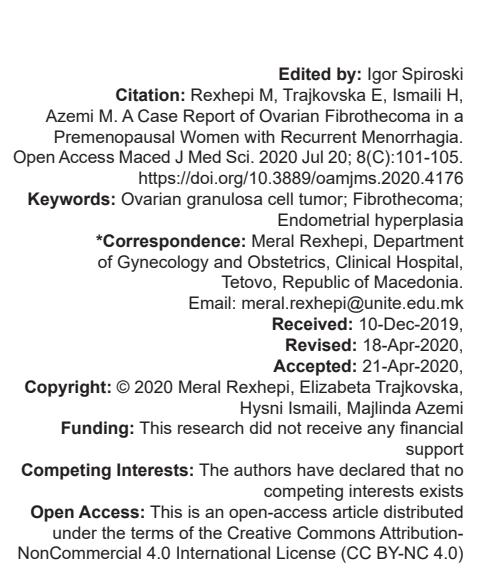

Abstract

BACKGROUND: Ovarian fibrothecoma is a rare, benign, sex cord-stromal neoplasm, with a typically unilatera location in the ovary, characterized by mixed features of both fibroma and thecoma. Ovarian fibrothecoma is uncommon tumor of gonadal stromal cell origin accounting for $3-4 \%$ of all ovarian tumours.

CASE PRESENTATION: We presented a rare case of a 46-year-old patient with recurrent menorrhagia in the past two years with no previous medical, surgical or gynecological history. She underwent two times curettage procedures. At the admission to hospital ultrasonography showed a homogenous solid right ovarian mass of size $2.5 \mathrm{~cm} \times 3.5 \mathrm{~cm}$. Endometrial curettage revealed simple hyperplasia of the endometrium. Diagnostic evaluation and surgical management are discussed along with a brief review of the literature. Total abdominal hysterectomy with bilateral salpingo-oophorectomy was carried out. Histopathology confirmed fibrothecoma of the ovary, proliferative endometrium with hyperplasia without atypia and multiple uterine fibroids.

CONCLUSION: In all patients presenting with recurrent menorrhagia and adnexal tumor the possibility of a granulosa cell tumor must be kept in mind during evaluation.

\section{Introduction}

Ovarian fibromas/fibrothecomas belong to sex cord-stromal tumors. They are solid benign tumors of the ovary, accounting for $1-4.7 \%$ of all ovarian neoplasms [1]. About $15 \%$ of affected patients develop endometrial hyperplasia $(\mathrm{EH})$ and $20 \%$ are diagnosed with endometrial cancer [2]. In very rare cases has been reported the co-existence of this tumors with uterine fibroids [3], [4]. About $10 \%-15 \%$ of ovarian fibrothecomas can be combined with ascites; however, less than $1 \%$ are combined with both ascites and hydrothorax, known as Meigs syndrome which disappears spontaneously after the tumor be removed [5]. Histologically, fibromas are composed of variable amounts of collagen from entirely spindle, oval, or round cells. The comas resemble theca interna cells of the ovary and are composed of lipids. There is a large histological and immunohistochemical overlap between the two structures that resulted in the term "fibrothecoma" [6]. These tumors affect all age groups and in $70 \%$ of the cases, the patients are diagnosed as having Stage I lesions at presentation, contrary to the epithelial ovarian tumors where patients present with Stage III or IV disease [7]. The pre-operative diagnostic rate of ovarian granulose cell tumors is rather low due to its low incidence, diverse clinical syndromes, and the great differences existing in tumor size, shape, and internal components. It is, therefore, often misdiagnosed as uterine myoma. When the tumor size is large, with ascites or even hydrothorax, and an elevated cancer antigen 125 (CA 125) level, it is probably misdiagnosed as malignancy [8]. Here, we present a rare case of unilateral ovarian fibrothecoma in a 46-year-old woman who presented with premenopausal bleeding in the past 2 years.

\section{Case Report}

A 46-year-old premenopausal multiparous woman, with previous three normal vaginal deliveries, married, with no significant personal or family history, presented to gynecology department with recurrent uterine bleeding in the past 2 years. These symptoms were accompanied by lower abdominal pain and discomfort for the past 6 months' duration. The abdominal pain was a dull ache in the right lower abdomen which propagated to the back. 
Pelvic examination revealed an enlarged anteverted uterus and a solid right ovarian mass of 3-4 cm size which it was confirmed by pelvic ultrasound scan (Figure 1).

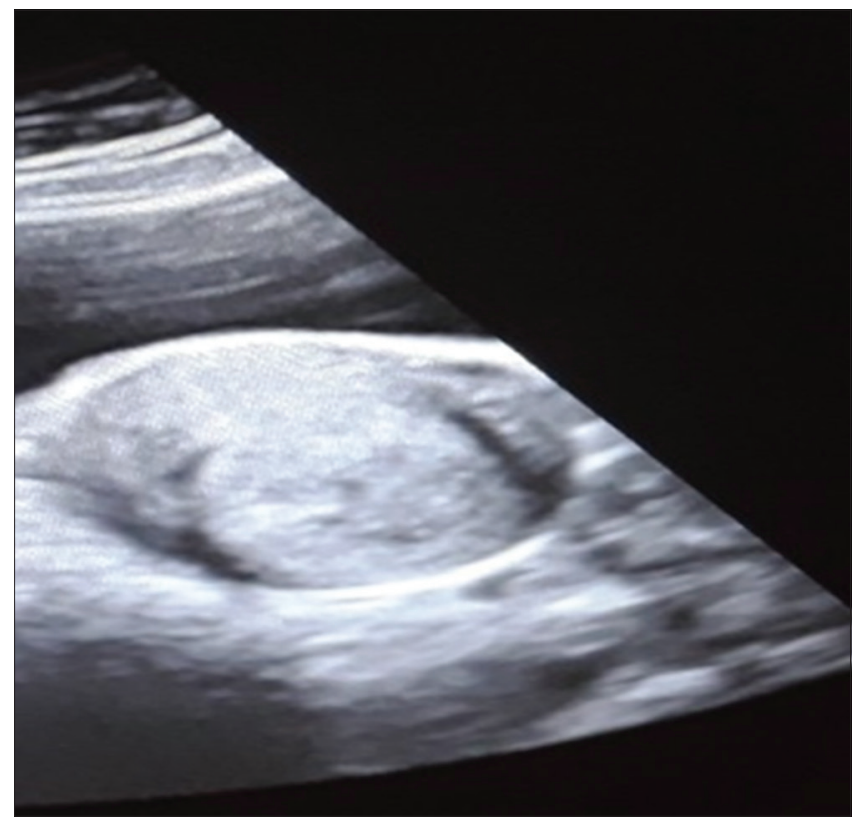

Figure 1: Ovarian fibrothecoma on ultrasound

Transvaginal ultrasound examination suggested the presence of a solid, movable, and non-homogenous echoic mass $(3.5 \times 2.8 \mathrm{~cm})$ originated from the right ovary. It was a solid mass with an intact capsule. No pathologic findings within the left ovary were found. A multiple intramural uterine fibroids were identified (Figure 2). No ascites was detected. Liver and the other abdominal organs were normal. She did not notice a significant change in her body weight or appetite. Her blood pressure was 135/90 mmHg. Her respiratory and cardiovascular systems were normal. The history of the disease was for the past 2 years. She underwent 2 times curettage procedures, without improvement of bleeding.

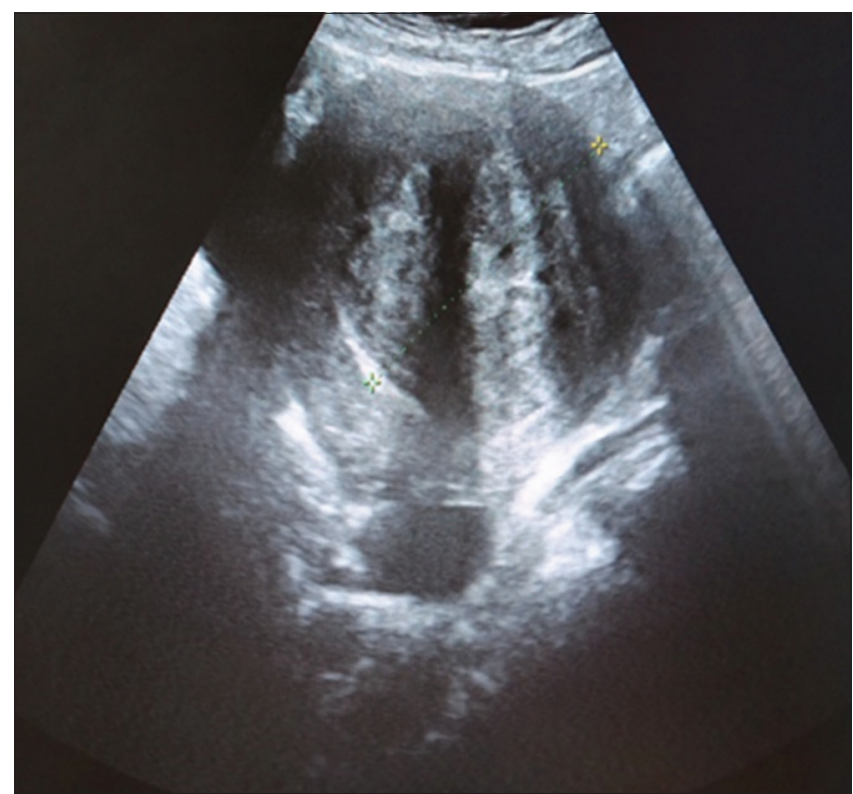

Figure 2: Ultrasound image of uterine fibroids
The results seem $\mathrm{EH}$ without cellular atypia. She had already tried conservative treatment, which had not improved her symptoms. Papanicolaou test excluded any microscopic modification of the uterine cervix. Laboratory tests including carcinoembryonic antigen and $\alpha$-fetoprotein were normal. CA 125 level was in normal range.

Treatment options were discussed with the patient after which she decided for hysterectomy.

A staging laparotomy was done. There was no ascites intraoperatively. Uterus appeared enlarged with multiple small fibroids. The right ovary was about $4 \times$ $3 \mathrm{~cm}$ in size, solid in appearance with an attached solid tumor formation. The left ovary appeared normal. Pouch of Douglas, omentum, intestinal surface, peritoneum, and other pelvic and abdominal viscera were free of tumor deposits. Retroperitoneal lymph nodes were not enlarged. Total abdominal hysterectomy with bilateral salpingo-oophorectomy was performed.

Histopathological examination detected enlarged uterus with endometrial polyposis and numerous myometrial leiomyomas. Uterus was $11 \times$ $3.5 \mathrm{~cm}$ with multiple fibroids of $1.5 \times 1 \mathrm{~cm}$ in size and one biggest fibroid $8 \times 6.5 \mathrm{~cm}$ in size in the anterior wall and uterine fundus; the endometrium was $1 \mathrm{~cm}$ in thickness and showed inactive glands with foci of hyperplasia without atypia and hemorrhage within the endometrial cavity. The myometrium was $2 \mathrm{~cm}$ in thickness and was unremarkable microscopically. The right ovary was $2.5 \times 3.5 \mathrm{~cm}$ size with an attached solid tumor formation $2 \times 2.5 \mathrm{~cm}$ with a small grainy surface with yellow and white areas (Figure 3 ). Its cut section was solid, grayish-white to grayish-yellow with cystic areas (Figure 4).

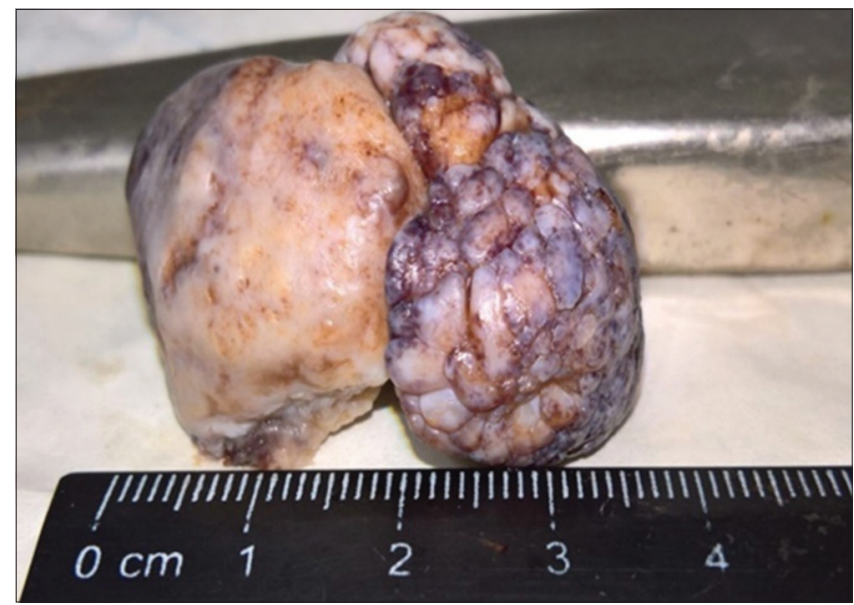

Figure 3: Macroscopic view of the tumor mass

The left ovary was normal measuring 2.5 $\times 2 \mathrm{~cm}$. Microscopic images of the tumor revealed uniform and cytologically bland-looking spindle cells with centrally placed nuclei without atypia arranged in fascicles (Figure 5). Most of the tumor cells had centrally placed oval to slightly angulated nuclei and a moderate amount of pale vacuolated cytoplasm (Figure 6). 


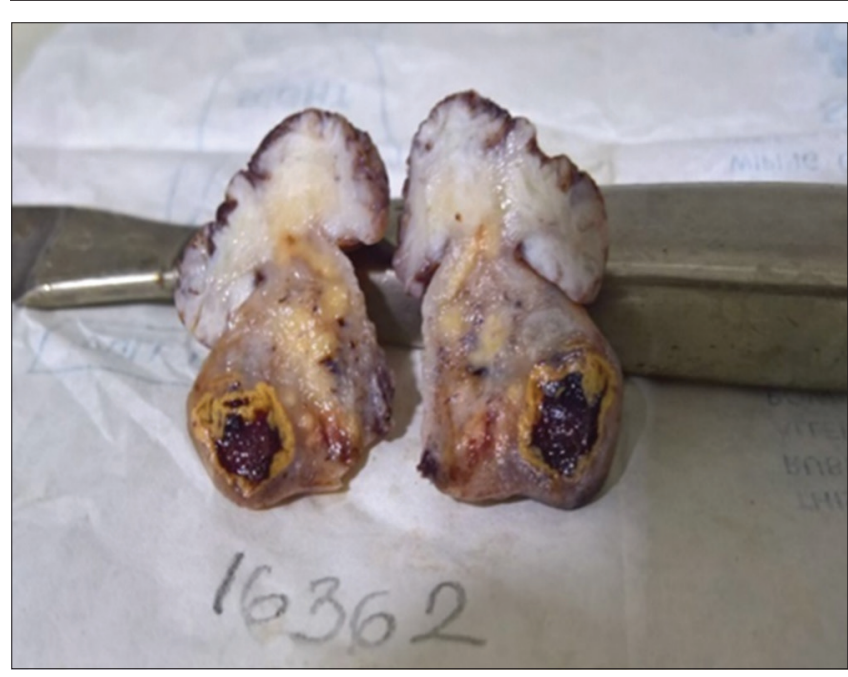

Figure 4: Cut surface of tumor with cystic change

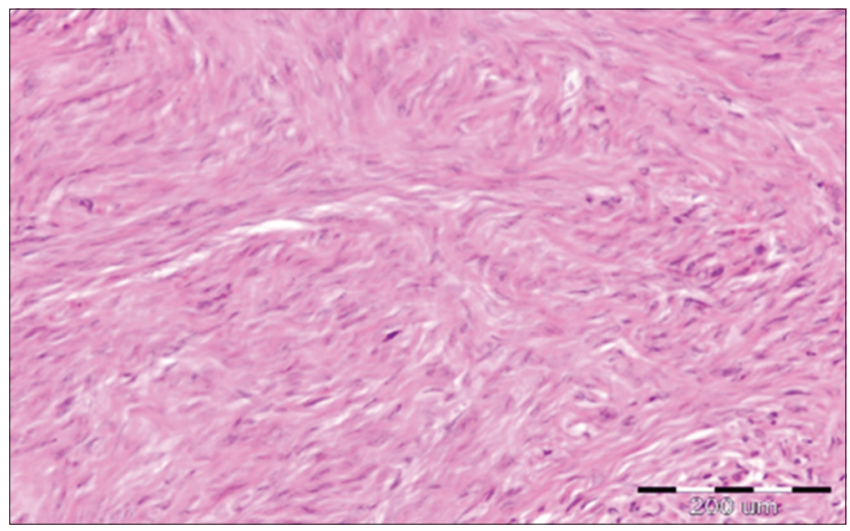

Figure 5: The fibrous component consists of cytologically bland spindle cells arranged in fascicles. $H E \times 20$

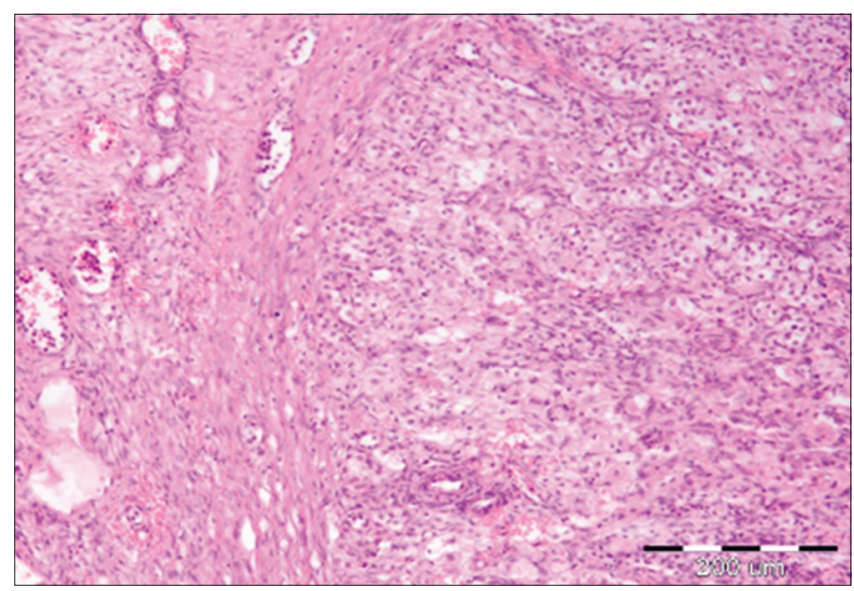

Figure 6: The thecomatous component consists of polygonal cells with vacuolated cytoplasm. HE $\times 20$

Nocapsularinfiltrationwasseen. Histopathological diagnosis was benign ovarian fibrothecoma. Uterine fibroids were composed predominantly of smooth muscle cells separated by variable amounts of fibrous connective tissue. Although there was no true capsule, well circumscribed and surrounded by a pseudocapsule.

Post-operative recovery was uneventful and the woman was discharged on the $7^{\text {th }}$ post-operative day. She is now on follow-up and doing well for the past 8 months' post-surgery with no complaints.

\section{Discussion}

Fibrothecomas are rare benign ovarian tumors extending from solid fibromas to lipid-rich thecomas and constituting the most common sex cord-stromal tumors of the ovary [9]. These account for about $4 \%$ of all ovarian tumors. The clinical presentation of ovarian fibrothecoma is relatively nonspecific such as pelvic and abdominal pain or distension; however, ovarian fibromas may be accompanied by two associations. The first is called Meigs syndrome (ovarian fibroma, hydrothorax, and ascites). The second association is with basal cell nevus syndrome (bilateral ovarian fibromas, multiple basal cell carcinoma of skin, and odontogenic keratocysts) [10]. We do not find any of these conditions in our patient. Fibrothecomas are usually benign, unilateral and occur commonly in old age [11]. They occur often in postmenopausal women with a peak incidence between 50 and 55 years of age. Our patient was in premenopausal age with irregular and rare menstrual cycles. This tumor produces estrogen, reason for $\mathrm{EH}$, recurrence uterine bleeding, and early diagnosis. About $70 \%$ of tumors are hormone secreting [12]. The most common presentation in premenopausal and menopausal age group is abnormal uterine bleeding (53.7\%). Either it could present as postmenopausal bleeding (27.5\%), heavy or irregular menstruation $(26.2 \%)$, or amenorrhea [13]. Our case was associated with intermitted vaginal bleeding, abdominal pain, and $\mathrm{EH}$. When it comes to the most important prognostic factors of women diagnosed with ovarian granulosa cell tumors, it seems that prognosis is strongly influenced by the initial stage at diagnosis followed by the integrity of the ovarian capsule and the dimensions of the tumor [14]. In this case, the tumor size was small, without ascites, and with an intact capsule. Some studies reported benign ovarian thecoma associated with hydrothorax and elevated CA 125 tumor marker, which mimicked an ovarian malignancy [15], [16], [17]. In a study by Ramkumar et al., bilateral thecoma presented as premenopausal hirsutism with hyperandrogenism [18]. Pedunculated and intraligamentous leiomyomas, Brenner tumors, granulose cell tumors, and dysgerminomas should be considered as differential diagnosis [19]. Numanoglu et al. presented that there are no specific markers for accurate preoperative diagnosis of ovarian fibroma/ fibrothecoma. Depending on the menopausal status, serum CA-125 level, and ultrasonographic findings, risk of malignancy index scoring system does not aid clinicians in this issue either, with a high falsepositive rate and very love sensitivity [18]. The modality of treatment could be tumor excision alone, 
uni- or bilateral salpingo-oophorectomy with or without hysterectomy depending on the patient status, and the aggressiveness of the tumor [21], [22]. In the case that we present, total hysterectomy with bilateral salpingooophorectomy was performed, because of women's premenopausal age, multiple uterine fibroids, and right ovarian tumor mass.

\section{Conclusion}

This case shows that the hormonal changes caused by fibrothecoma can cause recurrent premenopausal uterine bleeding, because of the continuous EH. Gynecologists should be aware of this type of tumor considering the difficulties in diagnosis. Most of them are benign, with a good prognosis. Surgery is the preferred treatment for fibrothecoma, and the present study suggested that the patient accepts the hysterectomy and bilateral salpingo-oophorectomy to avoid endometrial cancer in postmenopausal age. Cystectomy only can be performed in young women in the reproductive period. The patient had good recovery post-surgery with no complications. On follow-up, she did not have any health problem and she is in a good condition.

\section{Acknowledgment}

The authors would like to thank Dr. Vesna Janevska and Dr. Liljana Spasevska, Pathologists, for providing microscopic images of the tumor.

\section{References}

1. Obeidat RA, Aleshawi AJ, Obeidat HA, Al Bashir SM. A rare presentation of ovarian fibrothecoma in a middle age female: Case report. Int J Womens Health. 2019;11:149-52. https://doi. org/10.2147/ijwh.s191549

PMid:30881143

2. Podfigurna-Stopa A, Czyzyk A, Katulski K, Moszynski R, Sajdak S, Genazzani AR, et al. Recurrent endometrial hyperplasia as a presentation of estrogen-secreting thecoma case report and mini review of the literature. Gynecol Endocrinol. 2016;32(3):184-7. https://doi.org/10.3109/0951359 0.2015 .1113519

PMid:26585670

3. Matalliotaki C, Matalliotakis M, leromonachou P, Goulielmos G, Zervou M, Laliotis A, et al. Co existence of benign gynecological tumors with endometriosis in a group of 1,000 women. Oncol Lett. 2018;15(2):1529-32. https://doi.org/10.3892/ol.2017.7449 PMid:29434846
4. Krishnan D, Kumar K, Thomas A. Unilateral ovarian fibrothecoma with menorrhagia. Malaysian J Pathol. 2014;36(1):55-8.

PMid:24763236

5. Shen $Y$, Liang $Y$, Cheng X, Lu W, Xie X, Wan X. Ovarian fibroma/fibrothecoma with elevated serum CA125 level. A cohort of 66 cases. Medicine. 2018;97(34):e11926. https:// doi.org/10.1097/md.0000000000011926

PMid:30142807

6. Parwate N, Patel S, Arora R, Gupta M. Ovarian fibroma: A clinicopathological study of 23 cases with review of literature. J Obstet Gynecol India. 2016;66(6):460-5. https://doi.org/10.1007/ s13224-015-0717-6 PMid:27821988

7. Salemis N, Panagiotopoulos N, Papamichaill V, Kiriakopoulos K, Niakas E. Bilateral ovarian fibrothecoma. An uncommon cause of a large pelvic mass. Int J Surg Case Rep. 2011;2(3):29-31. https://doi.org/10.1016/j.ijscr.2010.07.005 PMid:22096681

8. Chen H, Liu Y, Li-Fei S, Jiang M, Yang ZF, Fang GP. Ovarian thecoma-fibroma groups: Clinical and sonographic features with pathological comparison J Ovarian Res. 2016;9:81. https://doi. org/10.1186/s13048-016-0291-2

9. Wu B, Peng J, Gu J, Cheng F, Mao J. MRI diagnosis of ovarian fibrothecomas: Tumour appearances and oestrogenic effect features. Br J Radiol. 2014;87(1038):20130634. https://doi. org/10.1259/bjr.20130634

PMid:24670054

10. Sharma S, Bansal R, Upreti S, Khare A, Sharma S, Agarwal D. Ovarian fibrothecoma with extensive cystic degeneration: Two case reports. Indian J Clin Pract. 2013;23(1):840-1. PMid:15786755

11. Chechia A, Attia L, Temime RB, Makhlouf T, Koubaa A. Incidence, clinical analysis, and management of ovarian fibromas and fibrothecomas. Am J Obstet Gynecol. 2008;199(5):473-e1-4. https://doi.org/10.1016/j.ajog.2008.03.053 PMid:18501324

12. Vyas N, Manjeera L, Rai S. Delayed menopause at the age of 64 due to ovarian granulosa cell tumor. J Clin Diagn Res. 2013;7(10):2306-7

PMid:24298512

13. Ayhan A, SIman MC, Velipasaoglu M, Sakinci M, Yuce $K$. Prognostic factors in adult granulosa cell tumors of the ovary: A retrospective analysis of 80 cases. J Gynecol Oncol. 2009;20(3):158-63. https://doi.org/10.3802/jgo.2009.20.3.158 PMid:19809549

14. Bacalbasa N, Stoica C, Popa I, Mirea G, Balescu I. Endometrial carcinoma associated with ovarian granulosa cell tumors--a case report. Anticancer Res. 2015;35(10):5547-50. PMid:26408724

15. Ting $Y$, Yang $L$, Juan $Z$, Xing $W$, Feng $Y X$. Ovarian thecoma with massive pleural effusion in postmenopausal women: A case report. Mol Clin Oncol. 2016;4(6):1003-5. https://doi. org/10.3892/mco.2016.853 PMid:27284435

16. Roberts P, Mozes S, Coburn N, Hamilton P, Gien LT. Retroperitoneal extraovarian fibrothecoma mimicking a malignant epithelial ovarian carcinoma. Case Rep Obstet Gynecol. 2012;2012:281745. https://doi.org/10.1155/2012/281745 PMid:22928131

17. Angeles RM, Salem FL, Sirota RL. A right ovarian mass in a 71-year-old woman with ascites and elevated CA 125 level. Arch Pathol Lab Med. 2005;129(5):701-2. PMid:15859649

18. Ramkumar S, Jyotsna VP, Mallick S, Kachhawa G, Kriplani A, 
Ammini AC. Bilateral thecoma presenting as premenopausal hirsutism: Laparoscopic removal. Indian J Endocrinol Metab. 2013;17(3):662-4. https://doi.org/10.4103/2230-8210.123561

PMid:24910832

19. Sheikh AA, Ganapathy H, Prijatham BO. Fibrothecoma a rare benign ovarian neoplasm. Sch J Med Case Rep. 2017;5(1):65-7.

20. Numanoglu C, Kuru O, Sakinci M, Akbayir O, Ulker V. Ovarian fibroma/fibrothecoma: Retrospective cohort study shows limited value risk of malignancy index score. Aust $\mathrm{N} Z \mathrm{~J}$ Obstet Gynaecol. 2013;53(3):287-92. https://doi.org/10.1111/ajo.12090 PMid:23611791
21. Cho YJ, Lee HS, Kim JM, Joo KY, Kim ML. Clinical characteristics and surgical management options for ovarian fibroma/fibrothecoma: A study of 97 cases. Gynecol Obstet Invest. 2013;76(3):182-7. https://doi.org/10.1159/000354555 PMid:24051436

22. Loue VS, Gbary E, Koui S, Akpa B, Kouassi A. Bilateral ovarian fibrothecoma associated with ascites, bilateral pleural effusion, and marked elevated serum CA-125. Case Rep Obst Gynecol. 2013;2013:189072. https://doi. org/10.1155/2013/189072

PMid:23431489 